Agron. Mesoam. 30(1):209-227. Enero-abril, 2019

ISSN 2215-3608, doi:10.15517/am.v30i1.33430

http://www.revistas.ucr.ac.cr/index.php/agromeso

\title{
Factores que afectan la producción en primera lactancia de vacas lecheras de Costa Rica ${ }^{1}$
}

\author{
Factors that affect the production in first lactation of dairy cattle of Costa Rica
}

\author{
Gloriana Castillo-Badilla² ,Bernardo Vargas-Leitón ${ }^{3}$, Frank Hueckmann-Voss ${ }^{4}$, Juan José Romero-Zúñiga ${ }^{2}$
}

1 Recibido: 28 de mayo, 2018. Aceptado: 19 de setiembre, 2018. Este trabajo formó parte de la tesis de maestría en Producción Animal Sostenible de la primera autora. Posgrado Regional en Ciencias Veterinarias Tropicales, Universidad Nacional, Heredia, Costa Rica.

2 Universidad Nacional, Costa Rica, Escuela de Medicina Veterinaria, Cátedra de Salud de Hato y Control de la Producción. Apdo. postal: 3043000 Heredia, Costa Rica. Teléfono: (506) 25624571; gloriana.castillo.badilla@una.cr (autor para correspondencia; https://orcid.org/00000002-9005-2423), juan.romero.zuniga@una.cr, Teléfono: (506) 25624565.

3 Universidad Nacional de Costa Rica, Posgrado Regional en Ciencias Veterinarias Tropicales. Apdo. postal: 304-3000 Heredia, Costa Rica. Teléfono: (506) 22773193. bernardo.vargas.leiton@una.cr

4 Consultor independiente. Apdo. postal: 304-3000 Heredia, Costa Rica. huecsedo@hotmail.com

\section{Resumen}

Introducción. El método de crianza que se brinda a una ternera, determina la vaca productora del futuro. Por lo tanto, las técnicas de salud, nutrición y alimentación pueden afectar el inicio y rendimiento de la vida productiva de una hembra bovina. Objetivo. El objetivo de este trabajo fue determinar el efecto de los factores del animal y del ambiente, modificables y no modificables, sobre la producción de la primera lactancia (PPL) en hatos lecheros especializados de Costa Rica. Materiales y métodos. Se realizó un estudio de cohorte retrospectivo. Se incluyeron 2747 vacas de razas Jersey y Holstein, con primer parto entre los años 2013 y 2015, de veintidós hatos lecheros especializados de diferentes zonas ecológicas de Costa Rica, con datos en el programa VAMPP Bovino. Se analizaron los datos mediante estadística descriptiva y un modelo lineal generalizado. Resultados. La PPL promedio a 305 días fue de $5485,8 \mathrm{~kg}( \pm 1547,8)$. Las variables no modificables del individuo, como la raza, presentaron efectos significativos sobre la PPL, con valores de $5360,1 \mathrm{~kg}$ (IC95\%: 5158,2-5562,1) y 4694,1 kg (IC95\%: 4578,5-4809,7) en la raza Holstein y Jersey, respectivamente. Se observó una tendencia a incrementar los niveles de producción conforme se aumentó la edad al primer parto hasta los veintiséis meses $(\mathrm{P}<0,001)$, después de lo cual se mantuvo estable. Se determinó un efecto significativo de la variable modificable de manejo $(\mathrm{P}<0,0001)$; fincas con protocolos de alta calidad de crianza de terneras produjeron $213,9 \mathrm{~kg}$ (PPL: 5809,0; IC95\%: 5570,6-6047,4) más de leche en su primera lactancia, que las novillas con una crianza media, y 1133,7 kg más que las de sistemas de baja calidad de manejo (PPL: 4676,3; IC95\%: 4158,3-5194,3). Conclusión. Estos resultados evidencian la influencia que tienen los métodos de crianza de terneras sobre el rendimiento productivo posterior del animal en sistemas tropicales. Las condiciones del medio ambiente tropical, incluyendo temperatura, humedad y precipitación, afectan de manera considerable el comportamiento productivo de las vacas lecheras.

Palabras clave: edad a primer parto, factor modificable, manejo de ganado, producción de leche.

\begin{abstract}
Introduction. The young calf rearing method, determines the dairy cow of the future. Therefore, health, feeding and housing techniques, influence the start and performance of the productive life of a dairy cow. Objective. The aim


of this work was to determine the effect of animal and environmental factors, modifiable and non-modifiable on the first lactation milk yield (FLM) in specialized dairy farms from Costa Rica. Materials and methods. A cohort retrospective study was conducted. A total of 2747 Jersey and Holstein cows, with age at first calving (AFC) between the years 2013 and 2015, belonging to twenty-two specialized dairy herds located in different ecological zones of Costa Rica, with data in the Bovine VAMPP program, were included in the study. All data in the present research was analyzed by descriptive analysis and a generalized linear model. Results. The average FLM at 305 days was $5485.8 \mathrm{~kg}( \pm 1547.8)$. Non-modifiable variables, like breed, had significant effects over FLM, with $5360.1 \mathrm{~kg}$ (CI95\%: 5158.2-5562.1) and 4694.1 (CI95\%: 4578.5-4809.7; P<0.001) for Holstein and Jersey breeds respectively. AFC, had a significant effect over FLM, were a tendency to increased milk production with higher AFC was found until twenty-six month of AFC, after that milk yield remain stable $(\mathrm{P}<0.001)$. Furthermore, the results showed a significant effect of management as a modifiable variable $(\mathrm{P}<0.0001)$ revealing that farms with high quality calf rearing protocols produced $213.9 \mathrm{~kg}$ (FML: 5809.0; CI95\%: 5570.6-6047.7) more milk in their first lactation than heifers raised under medium quality rearing and $1133.7 \mathrm{~kg}$ more milk than animals from low quality rearing programs (FML: 4676.3; CI95\%: 4158.35194.3). Conclusion.These results show that rearing factors affect the productive life time of dairy cows in tropical operations. Tropical environmental conditions, including temperature, humidity and precipitation, significantly affect the productive behavior of dairy cows.

Keywords: age at first calving, livestock management, milk production, modifiable factor.

\section{Introducción}

La rentabilidad de una explotación lechera se basa principalmente en los ingresos generados por la leche menos los costos de producción, alimentación y salud (Hultgren et al., 2011). El reto de incrementar los niveles de producción mientras se busca disminuir el impacto ambiental, ha instado a los productores a buscar altos rendimientos de la mano de protocolos de crianza efectivos, con el objetivo de minimizar los costos de producción y lograr altos índices de rendimiento productivo bajo sistemas de pastoreo (Coffey et al., 2016).

En el trópico, los sistemas de producción de leche con animales Bos taurus, están limitados por factores tanto genéticos como ambientales. Las condiciones del ambiente tropical, incluyendo temperatura, humedad y precipitación, afectan de manera considerable el comportamiento productivo de las vacas lecheras, disminuyendo su producción y condicionando el manejo de los animales, lo que limita la expresión del potencial genético (Carvajal-Hernández et al., 2002).

Distintos autores reportan que la producción de la primera lactancia (PPL) está influenciada por la tasa de crecimiento y también por la edad al primer parto (EPP), que tiene una correlación positiva con los niveles de producción de leche de la primera lactancia (Casas y Tewolde, 2001; Castillo-Badilla et al., 2013b; SalazarCarranza et al., 2014). El sector, a nivel mundial, con el fin de maximizar los niveles de producción, se ha enfocado en mantener la EPP entre los 21 y 24 meses, para disminuir los costos del periodo de desarrollo de la ternera y poder buscar una vida productiva más larga (Ettema y Santos, 2004; Haworth et al., 2008). Para el presente estudio, en particular, se tomó la EPP como una de las variables del animal de mayor peso, debido a la amplia discusión que se ha realizado sobre la correlación que existe entre la EPP y los niveles de producción de una hembra bovina (Pirlo et al., 2000; Castillo-Badilla et al., 2013b; Mohd-Nor et al., 2013; Salazar-Carranza et al., 2014).

Algunas variables que pueden afectar la PPL pueden llegar a ser modificadas de forma inmediata por el productor, haciendo posible la incorporación de cambios en las estrategias de crianza y el manejo interno de los animales de una finca en particular, para mejorar su rendimiento productivo y reproductivo. El término de variables 
modificables y no modificables se ha utilizado de forma frecuente en estudios de epidemiología y, en menor medida, en producción animal, para identificar elementos que pueden controlarse, modificarse o tratarse por el ser humano, para obtener un beneficio particular, como el manejo. Los atributos del individuo, la edad, la raza o la genética se consideran factores no modificables (Mee et al., 2014; Ibekwe, 2015).

$\mathrm{Al}$ identificar las variables modificables de la PPL y cuantificar su efecto, se pueden encontrar futuras áreas de mejora en la finca, para incrementar la eficiencia del sistema lechero, al garantizar que los animales presenten su máximo potencial genético manifestado en la producción de leche y longevidad dentro del hato (Salazar-Carranza et al., 2013; Krpálková et al., 2014). El incremento en la eficiencia de variables modificables, como las prácticas de manejo (alojamiento, salud y alimentación), pueden tener un impacto positivo sobre la economía de la finca, ya que estas garantizan un desarrollo óptimo de los animales, con un incremento subsecuente del rendimiento productivo y la longevidad del animal dentro del hato (Heinrichs y Heinrichs, 2011).

Cuando se estudian los factores que influyen sobre la producción de leche, los análisis se concentran en aquellas variables que se presentan en el animal adulto, como la temperatura, dieta, entre otros; sin embargo, muchas veces los efectos de la crianza en la capacidad productora de una hembra bovina se dejan por fuera. Características del alojamiento, como la temperatura, la humedad y las concentraciones de amoniaco, puede afectar directamente el desempeño productivo de una novilla (Heinrichs et al., 2005; Hultgren et al., 2008; Mohd-Nor et al., 2013), ya que influyen de forma directa en el estatus sanitario de la novilla y favorecen la aparición de enfermedades. Se reporta que terneras criadas con calostros de buena calidad, con concentraciones altas de inmunoglobulinas, presentaron producciones de leche a la primera lactancia superiores y presentaron una tasa de mortalidad inferior durante su primer ciclo productivo (Pettersson et al., 2001; Mcguirk, 2008).

En Costa Rica, se han conducido varios estudios del efecto de variables del animal, así como de los parámetros productivos, reproductivos y el ambiente, sobre la producción de la primera lactancia (Vargas y Ulloa, 2008a; 2008b; Castillo-Badilla et al., 2013a; Salazar-Carranza et al., 2013). Hasta la fecha, no existen estudios poblacionales que relacionen factores del individuo y del ambiente con los componentes de manejo durante el periodo de crianza, por lo cual, el objetivo de este trabajo fue determinar el efecto de los factores del animal y del ambiente, modificables y no modificables, sobre la producción de la primera lactancia (PPL), en hatos lecheros especializados de Costa Rica.

\section{Materiales y métodos}

\section{Diseño y población del estudio}

Se realizó un estudio cohorte retrospectivo, mediante el análisis de la información productiva y reproductiva de 2747 vacas pertenecientes a 22 fincas de las principales zonas lecheras de Costa Rica, que presentaron su primer parto entre los años 2013 y 2015, y con datos plausibles y completos para su procesamiento estadístico (dentro de rangos biológicos probables).

De las veintidós fincas, diez se ubicaron en la provincia de Alajuela, en Ciudad Quesada ( $n=3)$, Sucre $(n=1)$, Aguas Zarcas ( $n=3)$, Río Cuarto $(n=2)$ y Póas $(n=1)$. Cinco fincas se ubicaron en Cartago, cuatro en Heredia (Vara Blanca), y, por último, en las provincias de San José (Vásquez de Coronado, n=1), Puntarenas (Caldera, n=1) y Guanacaste (Guayabo, $n=1$ ), se analizó una finca en cada una.

Todas las fincas incluidas cuentan con información respecto a registros productivos, reproductivos, sanitarios y alimenticios; además de la anuencia del propietario para facilitar la información complementaria (protocolos de vacunación, desparasitación, análisis de suelos, pastos, entre otros). Los animales tenían que haber alcanzado su pico de producción de leche (aproximadamente dos meses posteriores al parto), con la finalidad de realizar la proyección a 305 días. 
Para fines de discusión, las fincas se catalogaron según su ubicación geográfica y características climáticas en explotaciones de altura o bajura, basada en la clasificación del MAG (2007). Las fincas de zonas bajas corresponden a sistemas ubicados en zonas con una altura menor a los $1300 \mathrm{msnm}$, con precipitaciones anuales de $4000 \mathrm{~mm}$ y con temperaturas elevadas; tales como la zona de San Carlos. Las fincas de altura, mantienen temperaturas ambientales más bajas, con precipitaciones promedio de 2700-1600 mm y con altitudes superiores a los $1300 \mathrm{msnm}$ (MAG, 2007; Vargas-Leitón et al., 2013).

\section{Recolección de datos y descripción de las variables}

Se utilizó la base de datos nacional de las fincas registradas en el programa VAMPP Bovino 3.0, en el Centro Regional de Informática para la Producción Animal Sostenible (CRIPAS), del Programa de Investigación en Medicina Poblacional (MedPob), de la Escuela de Medicina Veterinaria, Universidad Nacional (EMV-UNA) (Pérez et al., 1989; Baaijen y Pérez, 1995). También se incluyó información recolectada por medio de una encuesta diseñada ad hoc, a los responsables de los hatos seleccionados, con la finalidad de obtener información de las prácticas de manejo relacionadas con la crianza de reemplazos y estrategias reproductivas.

La variable dependiente fue la producción de la primera lactancia (PPL), y las variables independientes se clasificaron en cuatro categorías: asociadas al animal o al ambiente, y como modificables o no modificables. Estas últimas se refieren a la posibilidad de ser alterada, especialmente en corto plazo, por el ser humano (Cuadro 1). Dentro de esta clasificación, la variable de manejo se catalogó como modificable; las variables como edad al primer parto (EPP), raza, año, mes del primer parto y zona ecológica, según la clasificación de zonas de vida de Holdridge (1987), se clasificaron como no modificables.

Cuadro 1. Descripción de las variables del animal y del ambiente, modificables y no modificables, empleadas en el estudio cohorte retrospectivo de 2747 vacas lecheras de veintidós fincas de las principales zonas lecheras de Costa Rica. Primer parto entre 2013 y 2015.

Table 1. Description of the animal and environmental variables, modifiable and non-modifiable, used in the cohort retrospective study, of 2747 dairy cows of twenty-two milk farms of Costa Rica. First calving between 2013 and 2015.

\begin{tabular}{lccl}
\hline Variable & Condición & Escala de medición & \multicolumn{1}{c}{ Categorías } \\
\hline Raza & No modificable & Categórica & Holstein o Jersey \\
Año del primer parto & No modificable & Categórica & Según el año calendario \\
Mes del primer parto del animal & No modificable & Categórica & Según el mes del año: enero a diciembre \\
Edad al primer parto & No modificable & Categórica & 22 a 34 meses de edad (obtenidos por \\
& & & redondeo al más próximo) \\
Hato & No modificable & Categórica & Según el hato de procedencia \\
Manejo global & Modificable & Categórica & Alto: $>101$ puntos \\
& & & Medio: 75 y 101 puntos \\
& & & Bajo: <75 puntos \\
Zona ecológica & No modificable & Categórica & Según la clasificación de zonas de vida de \\
& & & Holdridge (1967) \\
\hline
\end{tabular}

Con el fin de categorizar las fincas según su nivel de manejo (alto, medio, bajo), se utilizaron 39 variables de la encuesta, relacionadas con el manejo de los reemplazos, en donde la información se clasificó en tres grandes áreas: salud, alojamiento y manejo nutricional de las terneras (Cuadro 2). 
En el área de salud se incluyeron variables relacionadas con el estatus sanitario del hato, tales como protocolos de vacunación, políticas de remplazo, higiene, visita regular de un médico veterinario, prevalencia de enfermedades gastrointestinales, respiratorias y onfaloflebitis, registro de muertes pre-destete y manejo de los casos clínicos. En el área de alojamiento se consideró el tipo de estabulado, si se alojaban de forma grupal o individual, el tipo de piso, si este era o no elevado, el tipo de cama, y la división entre una cuna y otra. En el área de alimentación se incluyeron variables como el tipo de leche ofrecida a la ternera (reemplazador o leche entera), y si esta se sometía a algún tipo de análisis determinado como medición de células somáticas, ausencia de mastitis o residuos de antibiótico, o si se pasteurizaba previo a ofrecerla a las terneras; igualmente, si la dieta de las terneras tenía aporte de concentrado, heno o pasto fresco.

A cada una de las variables incluidas por categoría (salud, alojamiento y alimentación) se les asignó una puntuación determinada según las condiciones observadas, con base en diferentes ponderaciones mediante escalas discretas asociadas a la importancia relativa de cada variable (Cuadro 2). De acuerdo con la escala utilizada, la máxima puntuación posible para una finca con condiciones óptimas en todas las variables, fue de 80 en el área de salud, 15 en el área de alojamiento y 27 en el área de alimentación, para un total de 122 en el manejo global. Seguidamente, se realizó la sumatoria de los puntajes otorgados para las tres áreas de manejo, para obtener la puntuación de la variable de manejo global. Para poder clasificar las fincas según el tipo de manejo, en alta, media o baja, se calculó el valor de los terciles, para utilizar los valores de la sumatoria como referencia para la categorización. Por lo tanto, se clasificaron como fincas con manejo alto a aquellas con más de 101 puntos (tercil superior), media con puntuación entre 75 y 101 y baja con menos de 75 puntos (tercil inferior) (Cuadro 1).

\section{Análisis estadístico}

Para el análisis del efecto de las variables de animal y ambiente sobre la PPL, se ejecutó un Modelo Lineal Generalizado. El modelo estadístico para la producción de la primera lactancia se describe a continuación:

$$
\mathrm{Y}=\mu+\beta_{1} \mathrm{~A}+\beta_{2} \mathrm{M}+\beta_{3} \mathrm{R}+\beta_{4} \mathrm{Mg}+\beta_{5} \mathrm{EPP}+\beta_{6} \mathrm{Z}+\beta_{7}(\mathrm{R} \times \mathrm{EPP})+\beta_{8}(\mathrm{R} * \mathrm{Mg})+\beta_{9}(\mathrm{ZxMg})+\beta_{10} \mathrm{H}(\mathrm{R} \times \mathrm{Mg})+\xi
$$

Donde:

Y: kg de producción de leche corregida a 305-días en Primera Lactancia (PPL).

$\mu$ : media general

$\beta_{1}$ A: efecto fijo del año del primer parto $(2013,2014,2015)$.

$\beta_{2} \mathrm{M}$ : efecto fijo del mes del primer parto (enero a diciembre).

$\mathrm{B}_{3} \mathrm{R}$ : efecto fijo de la raza (Holstein, Jersey).

$\beta_{4} \mathrm{Mg}$ : efecto fijo de las prácticas de manejo global (alta, media, baja).

$\beta_{5}$ EPP: efecto fijo de la edad al primer parto (en categorías mensuales desde 22 hasta 34 meses).

$\mathrm{B}_{6} \mathrm{Z}$ : efecto fijo de la zona ecológica.

$\mathrm{B}_{7}(\mathrm{R} \times \mathrm{EPP})$ : efecto fijo de la interacción de raza $\times$ edad al primer parto.

$\mathrm{B}_{8}(\mathrm{R} \times \mathrm{Mg})$ : efecto fijo de la interacción de raza $\times$ manejo global.

$\beta_{9}(\mathrm{ZxMg})$ : efecto fijo de la interacción de la zona ecológica $\mathrm{x}$ manejo global.

$\mathrm{B}_{10} \mathrm{H}(\mathrm{R} \times \mathrm{Mg})$ : efecto fijo del hato anidado dentro de grupos de raza $\times$ manejo global.

$\xi$ : error residual aleatorio.

Los análisis estadísticos se realizaron con el programa SAS versión 9.4, con su rutina GLIMMIX (SAS Institute, 2010). En el modelo, se asume una distribución normal para la variable de respuesta (PPL) y se utiliza una función de enlace identidad. 
Cuadro 2. Puntuaciones asignadas por categoría de las variables de manejo asociadas a las áreas de salud, alojamiento y alimentación, empleadas en el estudio cohorte retrospectivo de 2747 vacas lecheras de veintidós fincas de las principales zonas lecheras de Costa Rica. Primer parto entre 2013 y 2015.

Table 2. Assigned punctuation by management category, associated to health, housing and feeding, used in the cohort retrospective study, of 2747 dairy cows of twenty-two milk farms of Costa Rica. First calving between 2013 and 2015.

\begin{tabular}{|c|c|c|c|}
\hline Área & Variable de manejo & Descripción de categorías & $\begin{array}{c}\text { Pun- } \\
\text { tuación }\end{array}$ \\
\hline \multirow[t]{23}{*}{ Salud } & \multirow[t]{2}{*}{ Política de reemplazos } & Reemplazos se desarrollan en la finca y se adquieren de afuera. & 0 \\
\hline & & Reemplazos se desarrollan solo con animales nacidos en la finca. & 12 \\
\hline & \multirow[t]{2}{*}{ Calidad de higiene } & Desinfección superficial o nula. & 0 \\
\hline & & Desinfección profunda. & 6 \\
\hline & \multirow[t]{2}{*}{ Producto de limpieza } & Cal, carbolina, cloro, agua caliente o ningún producto. & 0 \\
\hline & & $\begin{array}{l}\text { Mezcla comercial de ácidos orgánicos, biocidas orgánicos, inorgánicos } \\
\text { y surfactantes. }\end{array}$ & 6 \\
\hline & \multirow[t]{2}{*}{ Separación de las crías } & Después de las 2 horas. & 0 \\
\hline & & Primeras 2 horas. & 5 \\
\hline & \multirow[t]{2}{*}{ Visita veterinaria } & Visita del médico veterinario poco frecuente (>30 días). & 0 \\
\hline & & Visita del médico veterinario cada 30 días o menos. & 8 \\
\hline & \multirow[t]{2}{*}{$\begin{array}{l}\text { Áreas de inspección del médico } \\
\text { veterinario }\end{array}$} & $\begin{array}{l}\text { No inspecciona el área de maternidad, registros de la finca y los ani- } \\
\text { males. }\end{array}$ & 0 \\
\hline & & Inspecciona el área de maternidad, registros de la finca y los animales. & 0 \\
\hline & \multirow{2}{*}{ Vacunas } & Únicamente Brucella. & 0 \\
\hline & & $\begin{array}{l}\text { Brucella, clostridial y agentes virales (IBR, BDV, parainfluenza, sincia- } \\
\text { tial bovino, leptospira). }\end{array}$ & 12 \\
\hline & \multirow[t]{2}{*}{ Edad de la vacunación } & $\geq 4$ meses. & 0 \\
\hline & & $<3$ meses. & 8 \\
\hline & \multirow{5}{*}{$\begin{array}{l}\text { Casos de enfermedades (por } \\
\text { cada diez terneras) } \\
\text { Mortalidad (casos por cada diez } \\
\text { terneras) }\end{array}$} & $\geq 3$ casos de onfaloflebitis, problemas respiratorios o diarrea. & 0 \\
\hline & & $\leq 2$ casos de onfaloflebitis, problemas respiratorios o diarrea. & 5 \\
\hline & & $>3$ casos de muerte los primeros 6 meses de vida. & 0 \\
\hline & & 1-2 casos de muerte los primeros 6 meses de vida. & 4 \\
\hline & & No hay casos de muerte los primeros 6 meses de vida. & 4 \\
\hline & \multirow[t]{2}{*}{ Atención de casos clínicos } & $\begin{array}{l}\text { No hay tratamiento temprano de síntomas, separación de los animales en- } \\
\text { fermos y desinfección profunda de las instalaciones donde alojan terneras } \\
\text { enfermas. }\end{array}$ & 0 \\
\hline & & $\begin{array}{l}\text { Tratamiento temprano de síntomas, separación de los animales enfermos y } \\
\text { desinfección profunda de las instalaciones donde alojan terneras enfermas. }\end{array}$ & 10 \\
\hline \multirow[t]{10}{*}{ Alojamiento } & \multirow[t]{2}{*}{ Estabulado } & Estabulado completo. & 0 \\
\hline & & Semiestabulado. & 1 \\
\hline & \multirow[t]{2}{*}{ Alojamiento } & Alojamiento grupal. & 0 \\
\hline & & Alojamiento individual. & 5 \\
\hline & \multirow[t]{2}{*}{ Piso } & Piso no elevado (concreto, madera). & 0 \\
\hline & & Piso elevado. & 2 \\
\hline & \multirow[t]{2}{*}{ Cama } & Cama de material orgánico. & 0 \\
\hline & & Cama de material inorgánico. & 3 \\
\hline & \multirow[t]{2}{*}{ Divisiones } & Divisiones abiertas. & 0 \\
\hline & & Divisiones sólidas de madera, cemento u otro. & 4 \\
\hline \multirow{8}{*}{$\begin{array}{l}\text { Alimenta- } \\
\text { ción }\end{array}$} & \multirow[t]{2}{*}{ Técnicas de alimentación } & Alimentador semiautomático. & 0 \\
\hline & & Chupón, balde o ambas. & 5 \\
\hline & \multirow[t]{2}{*}{ Tipo y calidad de leche } & Leche de descarte. & 0 \\
\hline & & Reemplazador o leche entera de buena calidad, o pasteurizada. & 8 \\
\hline & \multirow[t]{2}{*}{ Análisis de leche } & No hacen análisis de la leche. & 0 \\
\hline & & Mastitis, residuos de antibióticos, paratuberculosis, y leucosis. & 8 \\
\hline & \multirow[t]{2}{*}{ Ingredientes en la dieta } & Concentrado. & 0 \\
\hline & & Concentrado y heno o pasto fresco. & 6 \\
\hline
\end{tabular}




\section{Resultados}

La producción de leche promedio a 305 días en los animales estudiados fue de 5485,8 kg $( \pm 1547,8)$. La edad al primer parto (EPP) promedio fue de 27,4 meses $( \pm 4.7$; IC95\%=27,2-27,6 meses).

La heterogeneidad de la producción de leche de la primera lactancia se observa en la Figura 1, tanto dentro como entre las fincas estudiadas. Dentro de las fincas con mayores índices de producción estuvieron la finca 1 y la 20, ambas ubicadas en zonas de altura, específicamente en Vara Blanca y Sucre. Las fincas 8 y 18 presentaron las medias de producción más bajas entre los hatos estudiados, ambas explotaciones ubicadas en regiones de bajura (Figura 1).

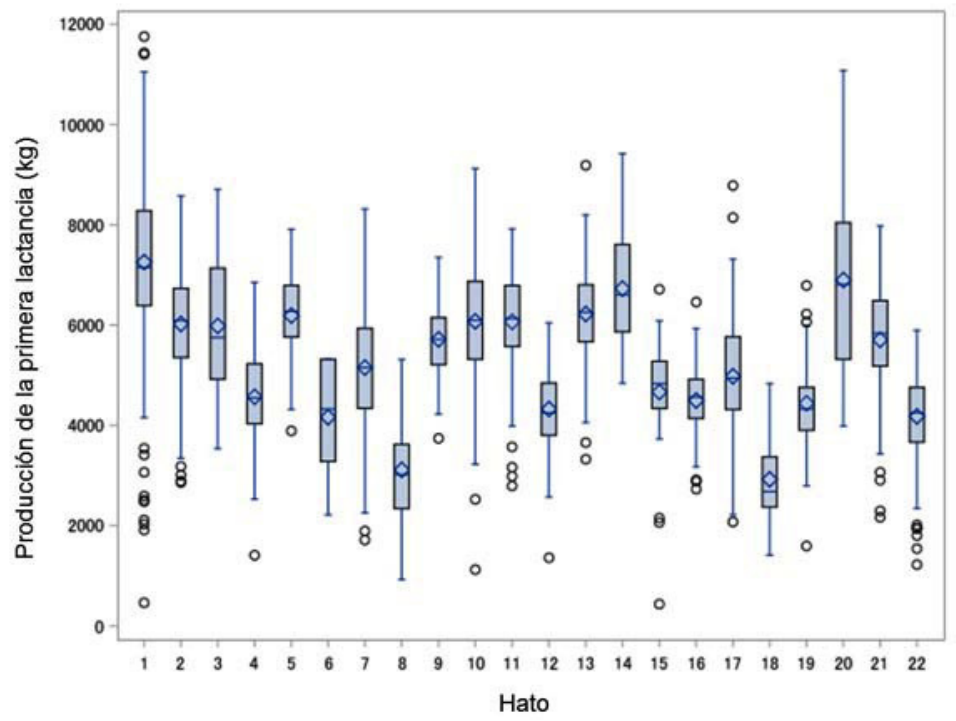

Figura 1. Diagramas de caja de la variable producción de la primera lactancia (PPL) en función del hato de procedencia. Estudio cohorte retrospectivo de 2747 vacas lecheras de veintidós fincas de las principales zonas lecheras de Costa Rica. Primer parto entre 2013 y 2015.

Figure 1. Box diagram for first lactation milk yield by herd of origin. Cohort retrospective study, of 2747 dairy cows of twenty-two milk farms of Costa Rica. First calving between 2013 and 2015.

El modelo lineal generalizado convergió satisfactoriamente $(\mathrm{P}<0,001)$, con un cumplimiento adecuado de los supuestos de normalidad, independencia y varianza constante de los residuos, demostrando un efecto significativo de la mayoría de las variables del animal y del ambiente sobre la PPL (Cuadro 3).

Las vacas Holstein presentaron una producción promedio a 305 días de 5360,1 kg (IC95\%: 5158,2-5562,1), $666 \mathrm{~kg}$ más que lo reportado para la raza Jersey (PPL: 4694,1kg; IC95\%: 4578,5-4809,7) (Cuadro 3). Con respecto al año del primer parto, las hembras con su primer parto en 2013 presentaron niveles de producción de leche ligeramente más elevados (PPL: 5120,4kg; IC95\%: 4992,8-5248,1), que las vacas que parieron por primera vez en los años 2014 y 2015 (Cuadro 3). Se pudo determinar que el mes del primer parto de la hembra puede afectar la PPL (P: 0,0011), lo que evidencia una tendencia a la baja en los meses de transición climática. Los animales que parieron por primera vez en los meses de junio, julio y agosto, registraron valores de producción de leche 
Cuadro 3. Medias marginales (e intervalos de confianza 95\%) de la producción de la primera lactancia (PPL, kg) para los distintos estratos de los factores relacionados con el animal y ambiente. Estudio cohorte retrospectivo de 2747 vacas lecheras de veintidós fincas de las principales zonas lecheras de Costa Rica. Primer parto entre 2013 y 2015.

Table 3. Marginal means (and confidence intervals 95\%) of first lactation milk yield for different strata of the factors related to animal and environment, used in the cohort retrospective study, of 2747 dairy cows of twenty-two milk farms of Costa Rica. First calving between 2013 and 2015.

\begin{tabular}{lccccc}
\hline Factor & Estrato & Media marginal & \multicolumn{2}{c}{ Intervalo de confianza 95\% } & Valor de P \\
\hline \multirow{4}{*}{ Raza } & & & LI & LS & \\
& Holstein & 5360,1 & 5158,2 & 5562,1 & $<, 0001$ \\
\hline Año del primer parto & Jersey & 4694,1 & 4578,5 & 4809,7 & \\
& 2013 & 5120,4 & 4992,8 & 5248,1 & 0,0014 \\
& 2014 & 4941,9 & 4813,8 & 5070,1 & \\
\hline Mes del primer parto & 2015 & 5019,0 & 4885,5 & 5152,5 & \\
& Enero & 5201,7 & 5036,8 & 5366,7 & 0,0011 \\
& Febrero & 5025,9 & 4850,8 & 5200,9 & \\
& Marzo & 5204,1 & 5025,0 & 5383,2 & \\
& Abril & 5017,9 & 4839,6 & 5196,1 & \\
& Mayo & 4997,8 & 4820,7 & 5174,8 & \\
& Junio & 4937,6 & 4761,9 & 5113,3 & \\
& Julio & 4915,3 & 4734,0 & 5096,7 & \\
& Agosto & 4810,7 & 4638,4 & 4982,9 & \\
& Septiembre & 4970,8 & 4790,4 & 5151,2 & \\
& Octubre & 5092,3 & 4917,7 & 5266,9 & \\
& Noviembre & 5016,9 & 4843,3 & 5190,6 & \\
& Diciembre & 5134,6 & 4957,8 & 5311,3 & \\
\hline Manejo global & Alto & 5837,5 & 5662,1 & 6012,8 & \\
& Medio & 5224,0 & 5103,5 & 5344,6 & \\
& Bajo & 4019,9 & 3747,6 & 4292,1 & \\
\hline
\end{tabular}

* $\mathrm{P}=$ valor de $\mathrm{P}$ para el efecto del factor correspondiente. $\mathrm{LI}=$ límite inferior. $\mathrm{LS}=$ límite superior $/ * \mathrm{P}=\mathrm{P}$ value for the corresponding factor. $\mathrm{LI}=$ lower limit. LS= upper limit.

más bajos, con producciones de 4937,6 kg (IC95\%:4761,9-5113,3), 4915,3 kg (IC95\%:4734,0-5096,7) y 4810,7 kg (IC95\%:4638,4-4982,9), respectivamente. Además, las vacas paridas en los meses de enero (PPL: 5201,7 kg; IC95\%: 5036,8-5366,7) y marzo (PPL: 5204,1 kg; IC95\%: 5025,0-5383,2) presentaron mayores niveles de producción de leche (Cuadro 3).

Con respecto a la EPP, para el presente estudio se consideró el analisis de la variable de forma individual y en interacción con la raza. Sin embargo, por la relación presente entre la EPP y la tasa de crecimiento, que a su vez se asocia directamente con las prácticas de crianza, se consideró la inclusión de la variable EPP en interacción con manejo en el modelo estádistico, pero la variable no mostró asociación $(\mathrm{P}=0,35)$ y se tomó la decisión de excluirla del modelo final.

Para EPP se observó una tendencia marcada de incremento en la producción de leche conforme se aumenta la EPP (Figura 2). A partir de los 26 meses de EPP, la PPL tendió a estabilizarse. Los animales que parieron por 


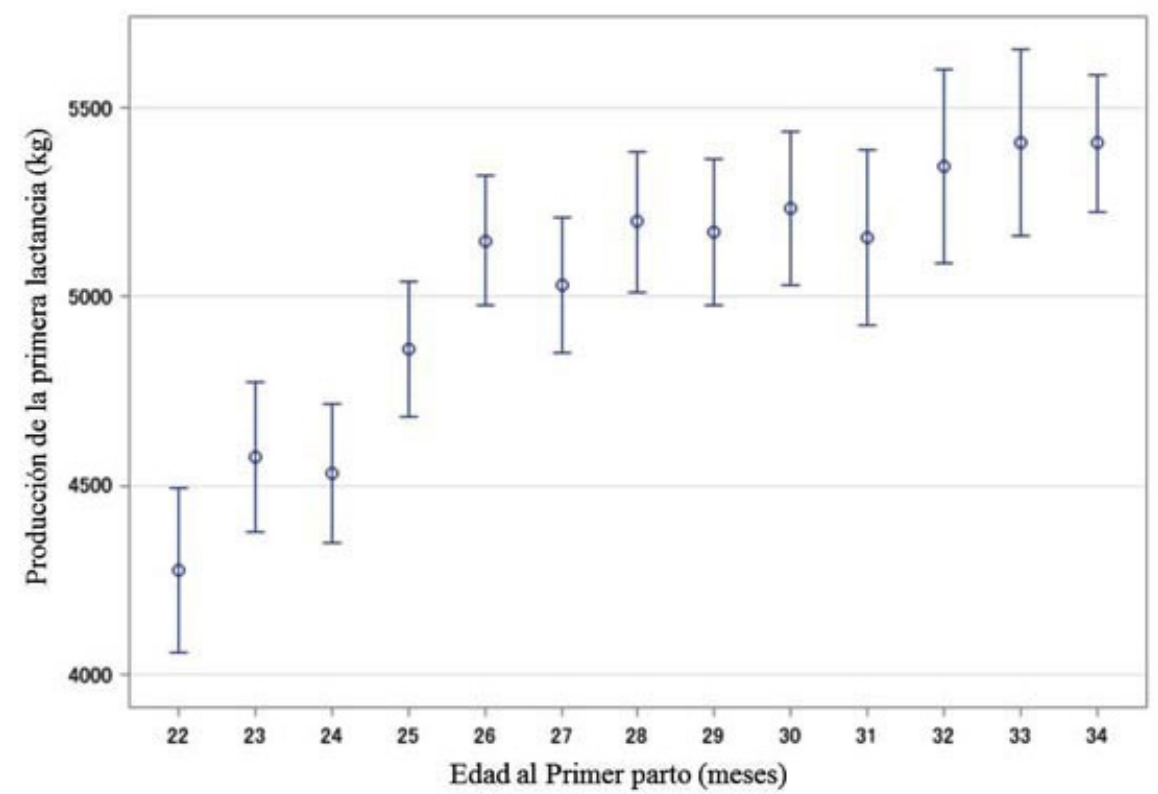

Figura 2. Medias marginales e intervalo de confianza 95\% para producción de la primera lactancia según categoría de edad a primer parto (meses). Estudio cohorte retrospectivo de 2747 vacas lecheras de veintidós fincas de las principales zonas lecheras de Costa Rica. Primer parto entre 2013 y 2015.

Figure 2. Marginal means and confidence interval $95 \%$ of first lactation milk yield by age at first calving category (months). Cohort retrospective study, of 2747 dairy cows of twenty-two milk farms of Costa Rica. Age at first calving between 2013-205.

primera vez a los 22 meses de edad, produjeron 1128,86 kg menos (PPL: 4278,1kg IC95\%: 406,6-4495,7) que las vacas paridas con 34 meses de edad (PPL: 5407,0; IC95\%: 5225,5-5588,5).

$\mathrm{Al}$ analizar el efecto de la EPP en interacción con la raza, se confirmó la tendencia mencionada anteriormente, de un incremento en la PPL conforme la EPP aumenta (Figura 3). Sin embargo, esta tendencia fue más marcada en las vacas Holstein, donde los animales con mayor EPP presentaron una mayor producción de leche en la primera lactancia (PPL: 5917,5 kg; IC95\%: 5661,5-6173,4), y difirieron de forma significativa de las novillas que llegaron muy jóvenes al primer parto, que presentaron una producción de leche a 305 días de 4145,8 kg (IC95\%: 3780,14511,7). Para la raza Jersey, la diferencia entre las novillas que parieron con 22 meses de edad (PPL: 4410,3; IC95\%: 4174,8-4646,0) y las paridas con 33 meses (PPL: 5054,8; IC95\%: 4701,3-5408,2), fue de 644 kg (Figura 3).

Debido a que el criterio de agrupación utilizado para la clasificación de hatos según el manejo global, correspondió a los terciles, la mayoría de fincas se ubicaron en categoría media (Cuadro 4). Al analizar las veintidós fincas según la variable parcial de salud, de un total de 80 puntos máximo, las fincas con eficiencia sanitaria alta obtuvieron un promedio de 72,2 puntos $( \pm 2,9), 59$ puntos $( \pm 6,6)$ para las de eficiencia media y 40,7 puntos $( \pm 1,5)$ para las fincas con manejo sanitario de baja calidad. Con respecto a las prácticas de alojamiento (puntaje máximo: 15) cuatro fincas presentaron buena calidad de las instalaciones, con un promedio de puntaje de 14 puntos $( \pm 0), 13$ fincas con alojamiento medio (promedio: 10,4 puntos; \pm 10 ) y cinco con mala calidad de alojamiento (promedio: 3,8 puntos; $\pm 2,4$ ). Seguidamente, las prácticas de alimentación (puntaje máximo: 27) presentaron un 22,7\% de fincas con un manejo considerado alto (promedio: 26 puntos; $\pm 2,23$ ); 63,6\% de explotaciones con manejo medio (promedio: 17 puntos; $\pm 3,7$ ) y 13,6\% de manejo alimentario deficiente (promedio: 10 puntos; $\pm 1,7$ ). 


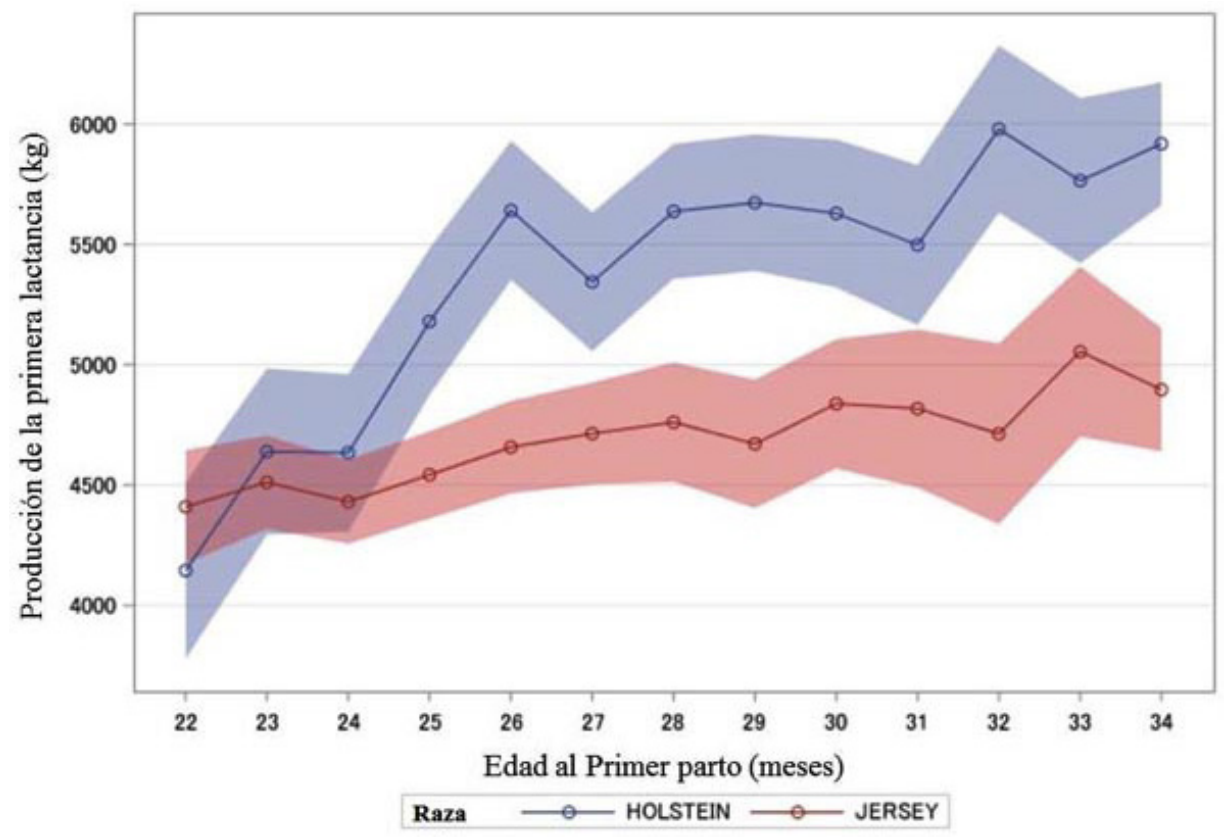

Figura 3. Medias marginales e intervalo de confianza 95\% de la producción de la primera lactancia para la interacción de la variable de edad al primer parto con la raza (Jersey y Holstein). Estudio cohorte retrospectivo de 2747 vacas lecheras de veintidós fincas de las principales zonas lecheras de Costa Rica. Primer parto entre 2013 y 2015.

Figure 3. Marginal mean and confidence interval 95\% of first lactation milk yield for the interaction between age at first calving and breed (Jersey and Holstein). Cohort retrospective study, of 2747 dairy cows of twenty-two milk farms of Costa Rica. First calving between 2013 and 2015.

Con respecto a la sumatoria de las variables parciales en manejo global; de las 22 fincas utilizadas, cuatro se clasificaron como explotaciones con manejo alto (Media: 105 puntos; \pm 1,41), 14 de manejo medio (Media: 89,07 puntos; $\pm 9,05$ ), y cuatro de manejo bajo (Media: 62,50 puntos; $\pm 11,56$ ), las cuales contaban con un total de 602, 1675 y 470 animales, respectivamente (Cuadro 4). Cabe mencionar que las fincas de manejo medio, tenían mayor cercanía de puntaje total a las fincas de manejo alto, que aquellas de baja calidad. Por ejemplo, las fincas de manejo global medio presentaron solo una diferencia de 16 puntos en el promedio con respecto a las fincas de manejo alto, contrario a lo observado con las bajas, que difirieron de las medias por 26 puntos.

La variable de manejo global, analizada en interacción con la raza en el modelo estadístico, evidenció una disminución de la producción de leche conforme los sistemas de crianza pierden eficiencia, tanto en animales Jersey como Holstein (Figura 4). Las terneras Holstein desarrolladas con manejo de alta calidad, produjeron 213,9 kg (PPL: 5809,0; IC95\%: 5570,6-6047,4) más de leche en su primera lactancia que las novillas con una crianza media, y 1132,7 kg más que las de sistemas de baja calidad de manejo (PPL: 4676,3; IC95\%: 4158,3-5194,3). En la raza Jersey se observó la misma tendencia, ya que las terneras procedentes de sistemas de crianza más eficiente presentaron $2503 \mathrm{~kg}$ de leche (PPL: 5865,9; IC95\%: 5608,1-6123,7), más que las criadas en sistemas deficientes (PPL: 3363,4; IC95\%: 3197,0-3529,8).

$\mathrm{Al}$ analizar el efecto fijo del hato en interacción con los grupos de manejo y raza, se encontró que, tanto para la raza Holstein (Figura 5) como para la raza Jersey (Figura 6), existió mucha variación en la PPL de los diferentes hatos, inclusive cuando pertenecían a un mismo nivel de manejo. 
Cuadro 4. Frecuencias absolutas y relativas (\%) de fincas y animales según variables de salud, alojamiento y alimentación, y según manejo global, en fincas lecheras especializadas de Costa Rica. Estudio cohorte retrospectivo de 2747 vacas lecheras pertenecientes a 22 fincas de las principales zonas lecheras de Costa Rica, que presentaron su primer parto entre los años 2013 y 2015

Table 4. Absolute and relative frequencies (\%) of farms and animals by health, housing and feeding variables, and according to global management, of milk farms from Costa Rica. Cohort retrospective study, of 2747 dairy cows of twenty-two milk farms of Costa Rica. First calving between 2013 and 2015.

\begin{tabular}{lccccccccc}
\hline Variable & Categoría & \# Fincas & \% Fincas & $\begin{array}{c}\# \\
\text { animales }\end{array}$ & $\begin{array}{c}\text { \% } \\
\text { animales }\end{array}$ & $\begin{array}{c}\text { Puntaje } \\
\text { promedio }\end{array}$ & DE & Mínimo & Máximo \\
\hline $\begin{array}{l}\text { Prácticas de } \\
\text { salud (puntaje } \\
\text { máximo= 80) }\end{array}$ & Alto & 5 & 22,7 & 656 & 23,9 & 72,2 & 2,9 & 70,0 & 77,0 \\
& Medio & 14 & 63,6 & 1878 & 68,4 & 59,0 & 6,6 & 47,0 & 69,0 \\
\hline $\begin{array}{l}\text { Prácticas de } \\
\text { alojamiento }\end{array}$ & Alto & 4 & 18,2 & 329 & 12,0 & 14,0 & 0,0 & 14,0 & 14,0 \\
$\begin{array}{l}\text { puntaje } \\
\text { máximo= 15) }\end{array}$ & Medio & 13 & 59,1 & 1932 & 70,3 & 10,4 & 10,0 & 9,0 & 12,0 \\
\hline $\begin{array}{l}\text { Prácticas de } \\
\text { alimentación } \\
\text { (puntaje }\end{array}$ & Alto & 5 & 22,7 & 486 & 17,7 & 3,8 & 2,4 & 0,0 & 6,0 \\
máximo= 27) & Medio & 14 & 63,6 & 1514 & 55,1 & 17,0 & 3,7 & 12,0 & 21,0 \\
\hline & & 3 & 13,6 & 409 & 14,9 & 10,0 & 1,7 & 8,0 & 11,0 \\
$\begin{array}{l}\text { Manejo global } \\
\text { (puntaje }\end{array}$ & Alto & 4 & 21,9 & 602 & 22,1 & 105,0 & 1,4 & 104,0 & 107,0 \\
máximo= 122) & Medio & 14 & 61,0 & 1675 & 60,2 & 89,0 & 9,1 & 75,0 & 101,0 \\
\hline Total & Bajo & 4 & 17,1 & 470 & 17,7 & 62,5 & 11,6 & 49,0 & 74,0 \\
\hline
\end{tabular}

DE: desviación estándar / DE: standard deviation.

Se pudo observar que la finca 1 correspondió al hato con mayor nivel de producción (PPL: 8295,5; IC95\%: 8095,6-8495,5), a pesar de presentar un tipo de manejo medio. Seguidamente, estuvieron las fincas 17 (PPL: 7604,4; IC95\%: 6163,5-9045,2) y 20 (PPL: 7475,3; IC95\%: 7226,0-7724,5), la primera de manejo medio y la segunda de un sistema de crianza deficiente. Además, la finca 18, que contaba con un sistema de desarrollo de terneras de baja calidad, presentó el valor más bajo de producción de leche con 2191,2kg (IC95\%: 160,4-4222,0) (Figura 5).

En el caso de los hatos de la raza Jersey, el comportamiento fue distinto (Figura 6), ya que las fincas con manejo de buena calidad correspondieron a las explotaciones con mayores niveles de producción de leche. La finca 14 fue la que obtuvo los valores superiores, con una producción para la primera lactancia de 6765,0 kg (IC95\%: 5852,6-7677,3), 4252,4 kg más que la finca 8, que reportó la producción de leche más baja (PPL: 2512,6; IC95\%: 2094,6-2930,6). 


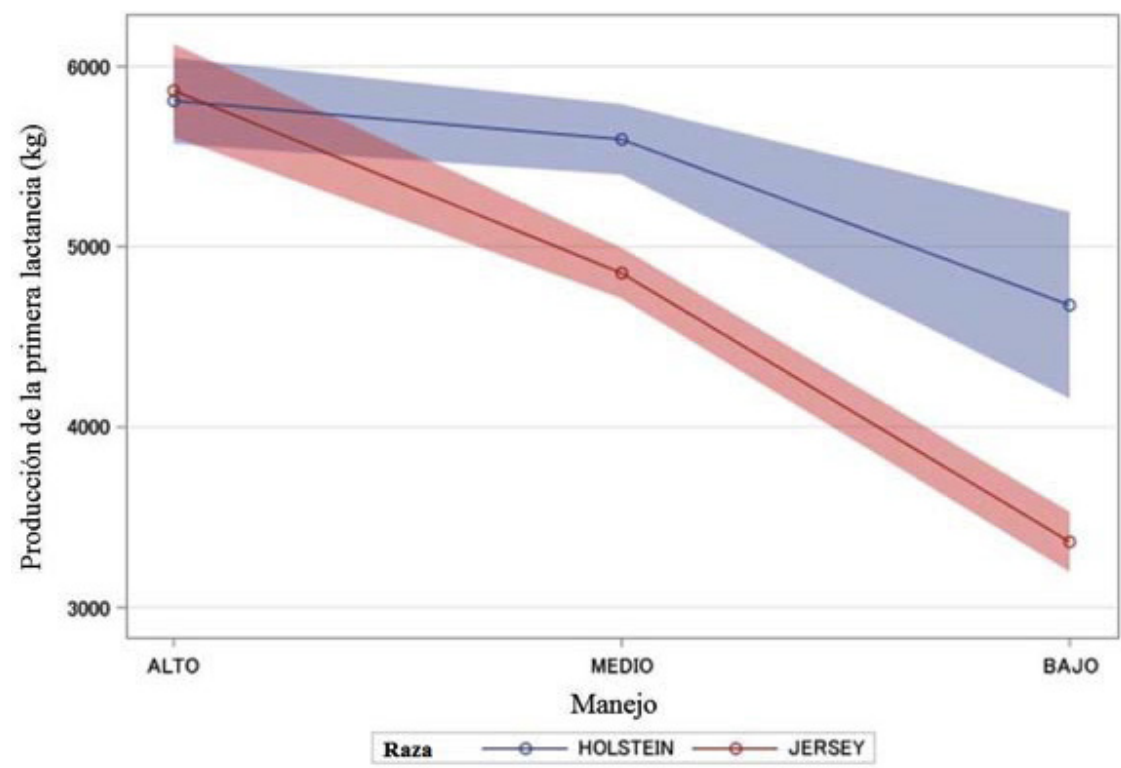

Figura 4. Medias marginales e intervalo de confianza 95\% de la producción de la primera lactancia para la interacción de la variable de manejo global (alto, medio y bajo) con la raza (Jersey y Holstein). Estudio cohorte retrospectivo de 2747 vacas lecheras de veintidós fincas de las principales zonas lecheras de Costa Rica. Primer parto entre 2013 y 2015.

Figure 4. Marginal means and confidence interval 95\% of first lactation milk yield for the interaction between global management variable ( high, medium, low) and breed (Jersey and Holstein). Cohort retrospective study, of 2747 dairy cows of twentytwo milk farms of Costa Rica. First calving between 2013 and 2015.

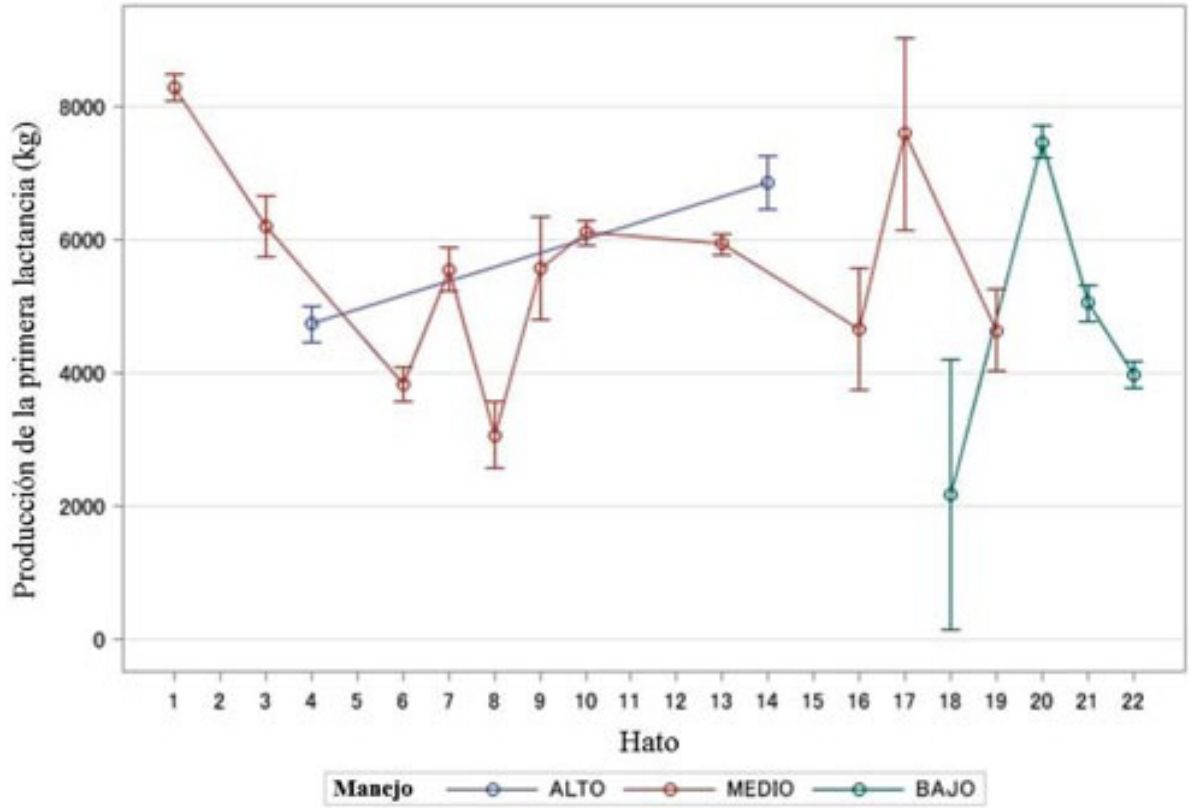

Figura 5. Medias marginales e intervalos de confianza 95\% para la variable producción de la primera lactancia en fincas con raza Holstein agrupadas según nivel de manejo (alto, medio, bajo). Estudio cohorte retrospectivo de 2747 vacas lecheras de veintidós fincas de las principales zonas lecheras de Costa Rica. Primer parto entre 2013 y 2015.

Figure 5. Marginal means and confidence intervals $95 \%$ of first lactation milk yield in Holstein farms grouped by management (high, medium, low). Cohort retrospective study, of 2747 dairy cows of twenty-two milk farms of Costa Rica. First calving between 2013 and 2015 . 


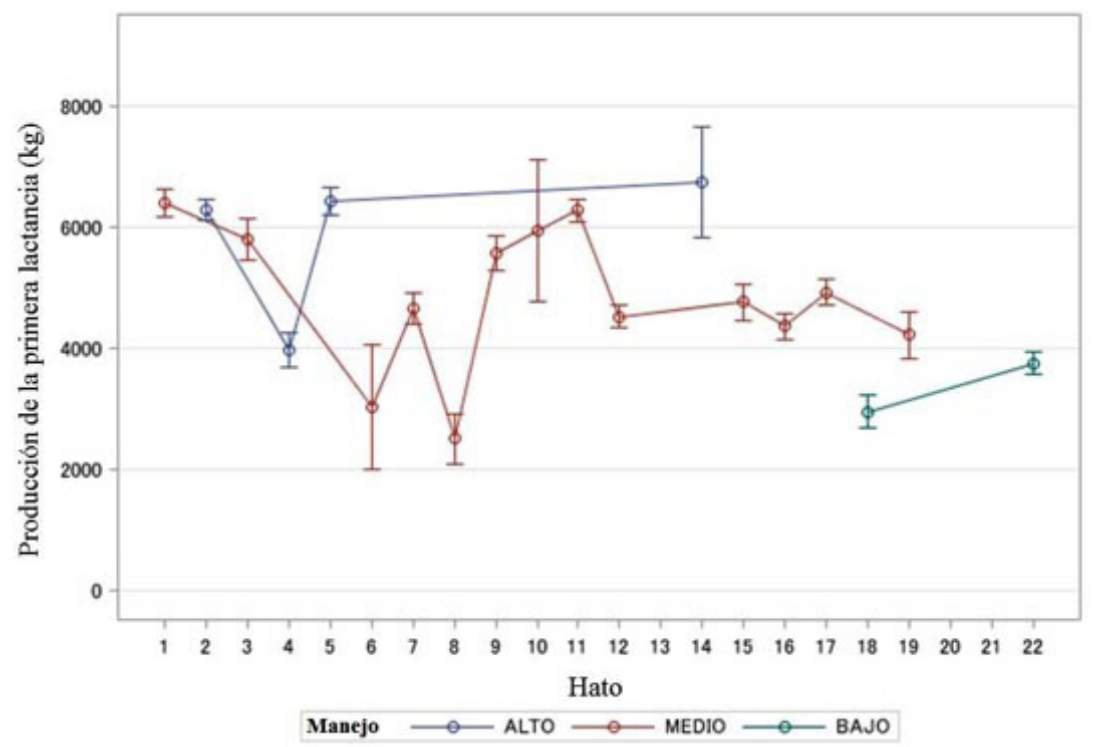

Figura 6. Medias marginales e intervalos de confianza 95\% para la variable producción de la primera lactancia en fincas con raza Jersey agrupadas según nivel de manejo (alto, medio, bajo). Estudio cohorte retrospectivo de 2747 vacas lecheras de veintidós fincas de las principales zonas lecheras de Costa Rica. Primer parto entre 2013 y 2015.

Figure 6. Marginal means and confidence intervals $95 \%$ for first lactation milk yield variable in Jersey farms grouped by management (high, medium, low). Cohort retrospective study, of 2747 dairy cows of twenty-two milk farms of Costa Rica. First calving between 2013 and 2015.

\section{Discusión}

Con respecto a la raza, los resultados fueron similares a lo reportado en estudios previos, en donde las vacas Holstein presentaron entre 12 y $19 \%$ más de producción de leche que las Jersey, y que los cruces entre ambas razas (Washburn et al., 2002; Coffey et al., 2016). La raza Holstein se considera una de las mayores productoras de leche, y mantiene de forma histórica mejores índices de producción láctea (Heins et al., 2008). Sin embargo, en muchos casos se observó una merma en el rendimiento de cualidades deseables en la leche, como la cantidad de sólidos, así como también una disminución del rendimiento reproductivo, a diferencia de la raza Jersey o del cruce de ambas razas (Heins et al., 2008; Vance et al., 2012).

El efecto del año del primer parto sobre la PPL se puede asociar con las características climáticas que se presentaron durante un determinado periodo. Al tratarse de hatos que mantienen sus animales en sistemas de pastoreo o semi estabulado, la calidad de las pasturas puede afectar el balance nutricional y por lo tanto, influir en los niveles de producción de leche (González, 2011). Los factores climáticos asociados al año tienen un efecto importante sobre la producción de leche, y actualmente las variaciones constantes producto del cambio climático han implicado mayores desventajas a nivel de la producción animal (Arias et al., 2008). Se ha analizado la influencia marcada que produce el ambiente en el cual se desarrollan los animales sobre mecanismos fisiológicos del animal, así como el comportamiento y la salud del ganado, que alterados pueden afectar significativamente el desempeño económico del mismo (Arias et al., 2008).

Cuando se analiza el comportamiento del mes del primer parto, se puede asociar la tendencia a tener menor nivel de producción de leche durante los meses de transición, con la ubicación de las fincas. Los hatos estudiados se encontraban distribuidos en diferentes ecozonas del país, por lo tanto, la distribución de las lluvias y la radiación en 
cada uno de los meses es variable. Estos factores favorecen la producción de forraje, ya que conforme se incrementa la precipitación, el pasto es más húmedo y su contenido de materia seca se reduce, afectando el desempeño productivo de los animales (Wing-Ching-Jones et al., 2008; Villalobos y Sánchez, 2010).

El objetivo primordial de los protocolos de desarrollo de reemplazos es la crianza de las terneras para formar parte del hato productivo, y que estas logren su máximo potencial en términos de producción de leche y longevidad dentro de la finca. La EPP juega un rol fundamental como parámetro evaluador de la calidad del manejo de una novilla durante su periodo prepuberal (Pirlo et al., 2000), esta refleja la tasa de crecimento de una novilla y el momento de su vida en la que está preparada para tener una primera lactancia exitosa, con altos valores de producción de leche (Ettema y Santos, 2004; Bach, 2011).

Varios autores han reportado los veinticuatro meses de vida como la edad idónea para el primer parto, con el fin de reducir el rubro económico de la etapa de desarrollo sin afectar el rendimiento productivo de la novilla, sin embargo, esto es posible únicamente manejando una buena alimentación y control del peso durante la etapa prepuberal (Meyer et al., 2004; Ettema y Santos, 2004). El efecto negativo que tiene el inicio temprano de la vida reproductiva sobre la producción de leche se asocia a distintos factores, tales como baja condición corporal durante la etapa prepuberal y al momento del parto (Pirlo et al., 2000).

La relación de la edad al primer parto (EPP) sobre la producción de leche ha sido ampliamente discutida anteriormente. Se ha reportado una relación directa significativa entre EPP y PPL (Vargas y Ulloa, 2008a; CastilloBadilla et al., 2013b; Salazar-Carranza et al., 2014). Animales con EPP menores a veintiséis meses representan una disminución de los costos de crianza, sin embargo, presentan un menor desempeño tanto en el nivel de producción de leche, como en el porcentaje de grasa y proteína (Pirlo et al., 2000; Nilforooshan y Edriss, 2004; Berry et al., 2008). No obstante, es importante tomar en cuenta que la producción de leche no se incrementó de forma sustancial cuando los animales tienen valores de EPP mayores a los veintiséis meses, por lo que, no es rentable que las hembras inicien su vida productiva posterior a ese momento.

Es importante relacionar el efecto del crecimiento y peso corporal con la EPP. En un estudio realizado anteriormente en Costa Rica por Solano-Patiño y Vargas-Leitón (1997), estos encontraron que la velocidad de crecimiento durante la crianza y la edad al primer parto mostraban un efecto lineal positivo sobre la PPL. En el presente estudio, la variable de peso corporal no pudo ser incluida en el modelo, debido a la falta de información registrada para las fincas incluidas.

$\mathrm{Al}$ analizar el efecto de la EPP en interacción con la raza, resultados similares han sido reportados por distintos autores, quienes caracterizan la raza Holstein por tener una tendencia a mayor producción de leche (Vargas y Ulloa, 2008a; Cooke et al., 2013). Distintos estudios también concuerdan en que a mayor EPP los valores de producción de leche se ven incrementados, tanto en animales Jersey como Holstein (Pirlo et al., 2000; Castillo-Badilla et al., 2013b; Salazar-Carranza et al., 2014).

Con respecto a la variable manejo, y cuando se examinan los resultados obtenidos por finca, se puede concluir que los rubros de alimentación y alojamiento fueron los que se acercaron más al puntaje máximo por categoría; lo que sugiere que es más probable que las fincas fallen más en el manejo sanitario de las terneras que en el alojamiento y alimentación. La mayoría de las fincas contaban con instalaciones para terneras que se acercan a las condiciones ideales, tales como alojamiento individual, piso elevado y divisiones cerradas. Además, la mayoría de las fincas manejaban protocolos de alimentación adecuados, con dietas para terneras que incluían leche (entera o reemplazador), concentrado y pasto fresco o heno, ingredientes esenciales para el desarrollo del animal. Sin embargo, el rubro de la variable de alimentación con mayor cantidad de problemas correspondió al análisis de la leche para alimentación de los reemplazos, en donde los análisis para antibióticos o mastitis fueron escasos o nulos en muchas de las fincas visitadas.

Es en el área de salud fue donde se encontraron la mayor cantidad de alteraciones que repercuten en el rendimiento futuro de una novilla. Las prácticas de higiene no eran las ideales en gran cantidad de las fincas 
visitadas, se empleaban productos de mala calidad o hubo una baja frecuencia de la limpieza de instalaciones, y el número de casos clínicos durante el periodo de desarrollo afectó la calificación parcial que tenían las fincas por categoría. Además, el manejo sanitario correspondió al rubro que más se le dificulta a los productores realizar con eficiencia, y uno de los que repercutió con mayor peso en los parámetros reproductivos, como la EPP.

La finalidad de los protocolos de crianza de terneras es intentar que el animal pueda manifestar su máximo potencial productivo a lo largo de su vida productiva, y esto se logra con buenos índices de salud, manejo alimentario e instalaciones apropiadas durante los primeros meses de vida de la novilla. El peso corporal y estatura al momento del parto, determina la eficiencia de la producción de leche en la primera lactancia de una novilla (Svensson y Hultgren, 2008). Los resultados obtenidos en el presente estudio reafirman que aquellos animales sometidos a mejores condiciones de manejo durante el periodo de crianza, lograron producir más leche en su primera lactancia que aquellos que se desarrollaron en sistemas con carencias de alimentación, alojamiento y salud. Esto se explica por el mejor desarrollo corporal y el peso que alcanzan las novillas al momento de su primera lactancia (Mohd-Nor et al., 2013). Sin embargo, la inclusión de las variables de peso y estatura, al momento del parto y al primer servicio al modelo estadístico no fue posible, ya que únicamente dos fincas de las veintidós estudiadas presentaron datos de peso en los animales, por lo tanto, se tuvo que excluir del modelo final. Al analizar el efecto fijo del hato en interacción con los grupos de manejo y raza, en el caso de los hatos de raza Holstein, las fincas con mayores niveles de producción, a pesar de que no corresponden a fincas con protocolos de crianza de terneras de óptima calidad, se encontraban en las tres zonas de altura: Vara Blanca, Sucre y Cartago. Esto es una característica que beneficia los índices de producción de leche, ya que cuentan con precipitaciones cercanas a los $2600 \mathrm{~mm}$ anuales y temperaturas promedio por debajo de los $19^{\circ} \mathrm{C}$ (Vargas-Leitón et al., 2013). Además, en las zonas de altura, las fincas se caracterizan por hacer uso de concentrados de buena calidad, suplementos y protocolos de fertilización de potreros, lo que les permite mantener altos índices de producción de leche, a pesar de tener fallas en el periodo de crianza.

Los efectos positivos de las características climáticas se asocian al índice de temperatura y humedad (ITH), herramienta que se ha venido utilizando con frecuencia para estimar el grado de estrés térmico al que se someten los animales de producción de leche. La producción de leche no se verá afectada siempre y cuando el ITH se encuentre en valores de 35-72, sin embargo, el consumo y la producción empiezan a disminuir cuando el ITH supera el 72 (Dikmen y Hansen, 2009; Bouraoui et al., 2002). Desafortunadamente, el ITH de las fincas no pudo ser utilizado en forma específica para cada finca, por lo que se optó por utilizar la clasificación de zonas de vida de Holdridge (1987) para el análisis del efecto de estas variables del ambiente físico, sin embargo, no hubo asociación estadística significativa, lo que lleva a pensar que son otras variables, como el método de crianza y manejo, las que mayor peso tuvieron sobre la producción.

La finca con menor nivel de PPL, correspondió a una finca ubicada en la zona de bajura, que además contaba con manejo del periodo de desarrollo de terneras de baja calidad. Cabe mencionar que, los sistemas ubicados en regiones de bajura se caracterizaron por hacer menos uso de fertilizantes, concentrados de buena calidad y suplementos, lo que se refleja en valores de producción de leche por vaca menores a lo reportado para zonas de altura, en donde la eficiencia del uso del terreno es mayor (Vargas-Leitón et al., 2013).

Otro aspecto que se puede asociar a la variabilidad de valores de la PPL en las fincas estudiadas es la genética que se utiliza en cada una de ellas. En Costa Rica, los hatos lecheros especializados tienden a utilizar razas lecheras puras o sus cruces, mientras que, las de doble propósito tienden a utilizar cruces de razas Bos indicus $\times$ Bos taurus (Vargas-Leitón et al., 2013). En muchos casos el nivel productivo de los animales de razas especializadas se ve sacrificado por su falta de adaptabilidad a las circunstancias ambientales o en el caso de los cruces, por utilizarse tipos raciales de bajo potencial productivo, esto aunado a la ausencia de una estrategia de mejoramiento genético (Vargas-Leitón et al., 2013). La selección de animales para un hato en particular, se relaciona mucho al sitio ecológico en donde se ubica la finca, por ejemplo, en climas templados la selección de las vacas se da con base en 
la producción de leche, sin embargo, en explotaciones de bajura, la adaptabilidad se vuelve un criterio de selección más importante, en donde se buscan animales con cascos oscuros y tolerancia a las altas temperaturas.

En el caso de los hatos de la raza Jersey, similar a lo reportado en la raza Holstein, las fincas con mejores índices de producción se ubicaron en regiones de altura del país, esto se puede relacionar, entre otros factores, al índice de temperatura y humedad (ITH) ya que, al aumentar la precipitación, la temperatura baja y la humedad relativa aumenta, dando una relación menor a 72 en el ITH, valor que no condiciona al animal a situación de estrés calórico y que le permite expresar su potencial genético en términos de producción de leche (Wing-Ching-Jones et al., 2008; Vargas-Leitón et al., 2013).

\section{Conclusiones}

Factores modificables como el manejo, que incluye las prácticas de salud, alimentación y características del alojamiento, influyeron de forma directa sobre la producción de la primera lactancia (PPL). Esto es de vital importancia para los productores, ya que pueden hacer uso del conocimiento adquirido para mejorar los protocolos de crianza, para garantizar mejores índices de producción de leche en el futuro, en especial aunado al reconocimiento de las variables no modificables como la raza y la edad al primer parto (EPP). Las variables modificables permiten realizar cambios de forma rápida, para corregir errores y evitar impactos negativos sobre el rendimiento productivo de las vacas lecheras e incrementar la eficiencia de los sistemas lecheros.

Con respecto a la edad al primer parto, es importante tomar en cuenta, que tanto la disminución como el incremento marcado traen aumentos en los costos de producción y reducción del rendimiento productivo de la hembra. Por otro lado, la raza es un punto clave a considerar cuando se recomienda la EPP en una finca productiva; por ese motivo, según los resultados obtenidos y considerando las condiciones tropicales del país, lo ideal es llevar a los animales a su primer parto con edades entre los veinticuatro y veintiséis meses, tiempo en el que los costos de crianza se mantienen bajos y la producción de la primera lactancia es eficiente.

\section{Literatura citada}

Arias, R., T. Mader, y P. Escobar. 2008. Factores climáticos que afectan el desempeño productivo del ganado bovino de carne y leche. Arch. Med. Vet. 40:7-22. doi:10.4067/S0301-732X2008000100002

Baaijen, M., and E. Pérez. 1995. Information technology in the Costa Rican dairy sector: A key instrument in extension and on-farm research. Agric. Hum. Values 12:45-51. doi:10.1007/BF02217296

Bach, A. 2011. Associations between several aspects of heifer development and dairy cow survivability to second lactation. J. Dairy Sci. 94:1052-1057. doi:10.3168/jds.2010-3633

Berry, D.P., P. Lonergan, S.T. Butler, A.R. Cromie, T. Fair, F. Mossa, and A.C. Evans. 2008. Negative influence of high maternal milk production before and after conception on offspring survival and milk production in dairy cattle. J. Dairy Sci. 91:329337. doi: $10.3168 /$ jds.2007-0438

Bouraoui, R., M. Lahmar, A. Majdoub, N. Djemali, and R. Belyea. 2002. The relationship of temperature-humidity index with milk production of dairy cows in a Mediterranean climate. Anim. Res. 51:479-491. doi:10.1051/animres:2002036

Carvajal-Hernández, M., E. Valencia-Heredia, y J. Segura-Correa. 2002. Duración de la lactancia y producción de leche de vacas Holstein en el Estado de Yucatán, México. Rev. Biomed. 13(1):25-31.

Casas, E., y A. Tewolde. 2001. Evaluación de características relacionadas con la eficiencia reproductiva de genotipos criollos lecheros en el trópico húmedo. Arch. Latinoam. Prod. Anim. 9(2):63-67. 
Castillo-Badilla, G., M. Salazar-Carranza, J. Murillo Herrera, y J.J. Romero Zúñiga. 2013a Factores que afectan la edad al primer parto en vacas Jersey de lechería especializada en Costa Rica. Rev. Cienc. Vet. 29(1):7-19.

Castillo-Badilla, G., M. Salazar-Carranza, J. Murillo-Herrera, y J.J. Romero-Zúñiga. 2013b. Efecto de la edad al primer parto sobre parámetros productivos en vacas Jersey de Costa Rica. Agron. Mesoam. 24:177-187. doi:10.15517/am.v24i1.9796

Coffey, E.L., B. Horan, R.D. Evans, and D.P. Berry. 2016. Milk production and fertility performance of Holstein, Friesian, and Jersey purebred cows and their respective crosses in seasonal-calving commercial farms. J. Dairy Sci. 99(7):5681-5689. doi:10.3168/jds.2015-10530

Cooke, J.S., Z. Cheng, N.E. Bourne, and D.C. Wathes. 2013. Association between growth rates, age at first calving and subsequent fertility, milk production and survival in Holstein-Friesian heifers. Open J. Anim. Sci. 3(1):1-12. doi:10.4236/ ojas.2013.31001

Dikmen, S., and P.J. Hansen. 2009. Is the temperature-humidity index the best indicator of heat stress in lactating dairy cows in a subtropical environment? J. Dairy Sci. 92:109-116. doi:10.3168/jds.2008-1370

Ettema, J.F., and J.E.P. Santos. 2004. Impact of age at calving on lactation, reproduction, health, and income in first-parity Holsteins on commercial farms. J. Dairy Sci. 87(8):2730-2742. doi:10.3168/jds.S0022-0302(04)73400-1

González, H. 2011. Fecha de parto: Factor fundamental en un sistema pastoril de producción de leche. Inf. Agrolechero $8(23): 14-17$.

Haworth, G., W. Tranter, J. Chuck, Z. Cheng, and D. Wathes. 2008. Relationships between age at first calving and first lactation milk yield, and lifetime productivity in dairy cows. Vet. Rec. 162:643-647. doi:10.1136/vr.162.20.643

Heinrichs, A.J., and B.S. Heinrichs. 2011. A prospective study of calf factors affecting first-lactation and lifetime milk production and age of cows when removed from the herd. J. Dairy Sci. 94:336-341. doi:10.3168/jds.2010-3170

Heinrichs, A.J., B.S. Heinrichs, O. Harel, G.W. Rogers, and N.T. Place. 2005. A prospective study of calf factors affecting age, body size, and body condition score at first calving of Holstein Dairy heifers. J. Dairy Sci. 88:2828-2835. doi:10.3168/ jds.S0022-0302(05)72963-5

Heins, B.J., L.B. Hansen, A.J. Seykora, D.G. Johnson, J.G. Linn, J.E. Romano, and A.R. Hazel. 2008. Crossbreds of Jersey × Holstein compared with pure Holsteins for production, fertility, and body and udder measurements during first lactation. J. Dairy Sci. 91:1270-1278. doi:10.3168/jds.2007-0564

Holdridge, LR. 1987. Ecología basada en zonas de vida. Trad. por Humberto Jiménez Saa. IICA, San José, CRC.

Hultgren, J., C. Svensson, D.O. Maizon, and P.A. Oltenacu. 2008. Rearing conditions, morbidity and breeding performance in dairy heifers in southwest Sweden. Prev. Vet. Med. 87:244-260. doi:10.1016/j.prevetmed.2008.04.003

Hultgren, J., C. Svensson, and M. Pehrsson. 2011. Rearing conditions and lifetime milk revenues in Swedish dairy cows. Livest. Sci. 137:108-115. doi:10.1016/j.livsci.2010.10.005

Ibekwe, R. 2015. Modifiable risk factors of hypertension and socio-demographic profile in Oghara, Delta State; prevalence and correlates. Ann. Med. Health Sci. Res. 5:71-77. doi:10.4103/2141-9248.149793

Krpálková, L., V.E. Cabrera, J. Kvapilík, J. Burdych, and P. Crump. 2014. Associations between age at first calving, rearing average daily weight gain, herd milk yield and dairy herd production, reproduction, and profitability. J. Dairy Sci. 97:6573-6582. doi:10.3168/jds.2013-7497

Mcguirk, S.M. 2008. Disease Management of Dairy Calves and Heifers. Vet. Clin. Food Anim. 24:139-153. doi:10.1016/j. cvfa.2007.10.003 
Mee, J.F., C. Sánchez-Miguel, and M. Doherty. 2014. Influence of modifiable risk factors on the incidence of stillbirth/perinatal mortality in dairy cattle. Vet. J. 199(1):19-23. doi:10.1016/j.tvj1.2013.08.004

Meyer, M.J., R.W. Everett, and M.E. Van-Amburgh. 2004. Reduced age at first calving: effects on lifetime production, longevity, and profitability. Kansas State University, NY, USA.

MAG (Ministerio de Agricultura y Ganadería). 2007. Agrocadena de leche. MAG, CRC. http://www.mag.go.cr/bibliotecavirtual/ E70-10453.pdf (consultado 11 oct. 2017).

Mohd-Nor, N., W. Steeneveld, T. van-Werven, M.C.M. Mourits, and H. Hogeveen. 2013. First-calving age and first-lactation milk production on Dutch dairy farms. J. Dairy Sci. 96:981-992. doi:10.3168/jds.2012-5741

Nilforooshan, M.A., and M.A. Edriss. 2004. Effect of age at first calving on some productive and longevity traits in Iranian Holsteins of the Isfahan province. J. Dairy Sci. 87:2130-2135. doi:10.3168/jds.S0022-0302(04)70032-6

Pérez, E., M. Baaijen, E. Capella, and H.W. Barkema. 1989. Development of a livestock information system for Costa Rica. In: H. Kuit et al., editor, 6th International Conference of Institutes for Tropical Veterinary Medicine. Utrecht, NED. p. 221-224.

Pettersson, K., C. Svensson, and P. Liberg. 2001. Housing, feeding and management of calves and replacement heifers in Swedish dairy herds. Acta Vet. Scand. 42:465-478. doi:10.1186/1751-0147-42-465

Pirlo, G., F. Miglior, and M. Speroni. 2000. Effect of age at first calving on production traits and on difference between milk yield returns and rearing costs in Italian Holsteins. J. Dairy Sci. 83:603-608. doi:10.3168/jds.S0022-0302(00)74919-8

Salazar-Carranza, M., G. Castillo-Badilla, J. Murillo-Herrera, F. Hueckmann-Voss, y J.J. Romero-Zúñiga. 2013. Edad al primer parto en vacas Holstein de lechería especializada en Costa Rica. Agron. Mesoam. 24:233-243. doi:10.15517/ am.v24i2.12522

Salazar-Carranza, M., G. Castillo-Badilla, J. Murillo-Herrera, F. Hueckmann-Voss, and J.J. Romero-Zúñiga. 2014. Effect of age at first calving on first lactation milk yield in Holstein cows from Costa Rican specialized dairy herds. Open J. Vet. Med. 4:197-203. doi:10.4236/ojvm.2014.49023

SAS Institute. 2010. SAS/STAT 9.22 User's Guide. SAS Institute Inc., Cary, NC, USA.

Solano-Patiño, C., y B. Vargas-Leitón. 1997. El crecimiento de novillas de reemplazo en fincas lecheras de Costa Rica: Tipificación del crecimiento de novillas Holstein y Jersey. Arch. Latinoam. Prod. Anim. 5(1):21-36.

Svensson, C., and J. Hultgren. 2008. Associations between housing, management, and morbidity during rearing and subsequent first-lactation milk production of dairy cows in southwest Sweden. J. Dairy Sci. 91:1510-1518. doi:10.3168/jds.2007-0235

Vance, E.R., C.P. Ferris, C.T. Elliott, H.M. Hartley, and D.J. Kilpatrick. 2012. Comparison of the performance of HolsteinFriesian and JerseyxHolstein-Friesian crossbred dairy cows within three contrasting grassland-based systems of milk production. Livest. Sci. 151:66-79. doi:10.3168/jds.2009-2791

Vargas, B., y J. Ulloa. 2008a. Relación entre curvas de crecimiento y parámetros reproductivos en grupos raciales lecheros de distintas zonas agroecológicas de Costa Rica. Livest. Res. Rural Dev. 20(7):103. http://www.lrrd.org/lrrd20/7/varg20103. htm (consultado 21 ago. 2017).

Vargas, B., y J. Ulloa. 2008b. Relación entre crecimiento y curvas de lactancia en grupos raciales lecheros de distintas zonas agroecológicas de Costa Rica. Livest. Res. Rural Dev. 20(8):122. http://www.lrrd.org/lrrd20/8/varg20122.htm (consultado 4 dic. 2017).

Vargas-Leitón, B., O. Solís-Guzmán, F. Saenz-Segura, y H. León-Higaldo. 2013. Caracterización y clasificación de hatos lecheros en Costa Rica mediante análisis multivariado. Agron. Mesoam. 24:257-275. doi:10.15517/am.v24i2.12525 
Villalobos, L., y J.M. Sánchez. 2010. Evaluación agronómica y nutricional del pasto Ryegrass Perenne Tetraploide (Lolium perenne) producido en lecherías de las zonas altas de Costa Rica. II. Valor nutricional. Agron. Costarricense 34:43-52.

Washburn, S.P., W.J. Silvia, C.H. Brown, B.T. Mcdaniel, and A.J. Mcallister. 2002. Trends in reproductive performance in Southeastern Holstein and Jersey DHI herds. J. Dairy Sci 85:244-251. doi:10.3168/jds.S0022-0302(02)74073-3

Wing-Ching-Jones, R., R. Pérez, y E. Salazar. 2008. Condiciones ambientales y producción de leche de un hato de ganado Jersey en el trópico húmedo: El caso del módulo lechero SDA/UCR. Agron. Costarricense 32(1):87-94. 